\title{
TINGKAT KEBUGARAN IBU HAMIL TRIMESTER 3 DI WILAYAH PUSKESMAS GAMBIRSARI SURAKARTA
}

\author{
Annisa Andriyani ${ }^{1}$, Wahyu Purwaningsih ${ }^{2}$, Siswanto ${ }^{3}$ \\ Sekolah Tinggi Ilmu Kesehatan 'Aisyiyah Surakarta \\ Akademi Keperawatan Insan Husada Surakarta \\ annisa7117@gmail.com, wahyuikd@gmail.com,siswantoarizal@gmaill.com
}

\begin{abstract}
Abstrak
Pendahuluan. Pemantauan kehamilan sangat menentukan dan membantu perencanaan proses persalinan. Disetiap kehamilan minimal dilakukan 4 kali permeriksaan Cakupan K4 di Surakarta telah mencapai $96 \%$ yang dirasa sudah bagus, namun demikian masih ada yang terlupakan tentang pengawasan dan pemantauan di kebugaran, selama ini belum ada penerapan atau pengukuran tentang tingkat kebugaran selama hamil sehingga saat persalinan akan membawa dampak terhadap kesehatan ibu.

Tujuan. Mengidentifikasi karakteristik berupa umur pekerjaan/aktivitas, paritas, IMT, dan riwayat persalinan dan tingkat kebugaran jasmani ibu hamil tri mester 3.

Metode. Jenis penelitian deskriptif observasional yang bertujuan untuk mendapatkan gambaran yang akurat dari sejumlah karakteristik masalah yang diteliti sedangkan pengambialan data digunakan metode cross sectional. Populasinya adalah seluruh ibu hamil tri mester 3 di wilayah Puskesmas Gambirsari Surakarta tiga bulan terakhir yaitu 161 orang sedang sampel ditentukan dengan rumus moe sebesar 98 orang. Instrumen yang digunakan yaitu lembar bantu untuk menulis tingkat kebugaran dan checklist untuk mengetahui karakteristik ibu

Hasil. Sebanyak 86 ibu hamil trimester $3(87,8 \%)$ tergolong usia tidak beresiko, sebanyak 81 ibu hamil trimester $3(82,7 \%)$ memiliki parietas multigravida, 80 ibu hamil trimester $3(81,6 \%)$ menunjukkan bahwa tingkat aktifitas aktif, 74 ibu hamil trimester 3(75,5\%) mayoritas memiliki IMT normal, 79 responden (80,6 \%)mempunyai riwayat persalinan spontan dan 88 ibu hamil trimester $3 \quad(89,9 \%)$ mempunyai tingkat kebugaran rendah.

Kesimpulan. Gambaran karakteristik ibu hamil di Wilayah Puskesmas Gambirsari Surakarta mayoritas ibu hamil tri mester 3 tergolong tidak beresiko, sebagian besar memiliki parietas multigravida, tingkat aktifitas pada aktifitas tergolong aktif, mayoritas memiliki IMT normal, sebagian besar mempunyai riwayat persalinan spontan. Tingkat kebugaran jasmani ibu hamil di Wilayah Puskesmas Gambirsari Surakarta sebagian besar mempunyai tingkat kebugaran rendah
\end{abstract}

Kata Kunci : Hamil, Trimester 3, Kebugaran. 


\begin{abstract}
Introduction. Pregnancy monitoring is very decisive and helps planning partus. At least four pregnancies check of K4 Coverage in Surakarta have reached $96 \%$, which is considered good, but there is still something to forget about supervision and monitoring in fitness, so far there has been no application or measurement of fitness levels during pregnancy so that delivery will bring impact on maternal health.

Purpose. Identify characteristics in terms of age of work / activity, parity, BMI, and maternal history and physical fitness level of triester pregnant women 3.

Method. This type of observational descriptive study aims to get an accurate picture of the characteristics of the problem under study while data collection was used cross sectional method.

Results. 86 trimester 3 pregnant women $(87.8 \%)$ were at no risk of age, as many as 81 third trimester pregnant women $(82.7 \%$ ) had multigravida patients, 80 trimester 3 pregnant women $(81,6 \%)$ shows that the level of activity is active, 74 mothers are pregnant $13 \mathrm{rd}$ trimester $(75.5 \%)$ the majority had a normal BMI, 79 respondents $(80.6 \%)$ had a history of spontaneous partus and 88 pregnant women in the third trimester $(89.9 \%)$ had a low fitness level.

Conclusion Characteristic description of pregnant women in The majority of Gambirsari Surakarta Community Health Center areas are 3 at risk of risk, most have multigravida patients, the activity level is classified as active, the majority have normal BMI, most have a history of spontaneous partus in the Gambirsari Surakarta Public Health Center has a low fitness level
\end{abstract}

Keywords: Pregnant, Trimester 3, Fitness. 
Pendahuluan. Jumlah Angka kematian ibu menurut Profil Kesehatan Kementrian Republik Indonesia pada tahun 2015, Pada tahun 1991-2007 AKI mengalami penurunan setiap tahunnya dari 350 per 100.000 turun menjadi 228 per 100.000 kelahiran hidup. Pada tahun 2007-2012 naik menjadi 359 per 100.000 kelahiran hidup. Angka Kematian Ibu menurun menjadi 305 per 100.000 kelahiran hidup dari tahun 2012-2015. Meskipun demikian pemerintah berupaya terus untuk mewujudkan target tujuan pembangunan

Millenium

Development Goals (MDGs) 2018 yakni sebesar 102 per 100.000 kelahiran hidup masih membutuhkan komitmen dan usaha keras yang terus menerus. Di Indonesia penyebab kematian langsung adalah perdarahan (30,3\%), hipertensi $(27,1) \%$, infeksi $(7,3 \%)$, partus lama $(1,8 \%)$, abortus $(1,6 \%)$, lain-lain $(40,8 \%)$.

Kasus kematian ibu Profil Kesehatan Jawa Tengah tahun 2015, Kabupaten/Kota dengan kasus kematian ibu tertinggi adalah kota
Brebes yaitu 52 kasus, diikuti kota Semarang 35 kasus, dan Tegal 33 kasus, Kabupaten/Kota dengan kasus kematian ibu terendah adalah Temanggung yaitu 3 kasus, diikuti kota Magelang 3 kasus, dan kota Surakarta 5 kasus. Sebesar 60,90 persen kematian maternal terjadi pada waktu nifas, pada waktu hamil sebesar 26,33 persen, dan pada waktu persalinan sebesar 12,76 persen. Penyebab kematian ibu adalah gangguan sistem peredaran darah (9,27\%), infeksi (2,76\%), hipertensi (26,34\%), perdarahan (21,14\%), lain-lain (40,49\%).

Angka kematian ibu Profil Kesehatan Kota Surakarta tahun 2016, didapatkan bahwa angka kematian ibu maternal masih fluktuasi. Kematian ibu mencapai puncak tertinggi yaitu 2010 yaitu sebesar 91,4 kemudian menurun pada tahun 2011, 2012, dan 2013. Sedangkan tahun 2014 ini belum mencapai target yang ditetapkan dalam rencana strategis Dinas Kesehatan Kota Surakarta tahun $2011-2015=71$.

Ibu hamil trimester III masuk kunjungan ibu hamil pada kontak 
minimal 4 kali selama masa kehamilan untuk mendapatkan pelayanan antenatal, yang terdiri atas minimal satu kali pada timester pertama, satu kali pada trimester kedua dan dua kali pada trimester ketiga (K4). Pemantauan kehamilan sangat menentukan dan membantu perencanaan proses persalinan. Disetiap Kehamilan minimal dilakukan 4 kali pertemuan. Terlihat di tabel 1.2 Cakupan K4 pada tri mester 3 di Jawa tengah kota surakarta adalah $96 \%$.

Di kota Surakarta terdiri 5 kecamatan yaitu kecamatan Laweyan, Kecamatan Serengan, Kecamatan Pasar Kliwon, Kecamatan Jebres, Kecamatan Banjarsari.Terlihat pada tabel 1.3 cakupan K4 tertinggi adalah di Kecamatan Banjarsari yaitu berjumlah 3.446. Sedangkan di Kecamatan Banjarsari Terdapat 6 wilayah kerja puskesmas dan K4 tertinggi adalah di Puskesmas Gambirsari terilat pada table 1.4. Dari data telah terlihat pemantauan yang bagus terutama di K4 namun demikian masih ada yang terlupakan tentang pengawasan dan pemantauan di kebugaran, selama belum ada penerapan atau pengukuran tentang tingkat kebugaran selama hamil sehingga saat persalinan akan membawa dampak terhadap kesehatan ibu. Padahal menurut banyak penelitihan bahwa ibu yang melakukan senam hamil,atau aktivitas fisik akan berdampak positif dalam proses persalinan.

Tujuan dari penelitian ini mengidentifikasi karakteristik berupa umur pekerjaan/aktivitas, paritas, IMT, dan riwayat persalinan dan tingkat kebugaran jasmani ibu hamil tri mester 3.

Metode. Jenis penelitian yang digunakan adalah deskriptif observasional. Penelitian deskriptif bertujuan untuk mendapatkan gambaran yang akurat dari sejumlah karakteristik masalah yang diteliti. Rancangan penelitihan yang digunakan menggunaakan metode pendekatan cross sectional. Populasinya adalah seluruh ibu hamil tri mester 3 di wilayah Puskesmas Gambirsari Surakarta tiga bulan terakhir yaitu 161 orang sedang sampel ditentukan dengan rumus moe sebesar 98 orang. Instrumen 
yang digunakan yaitu lembar bantu untuk menulis tingkat kebugaran dan checklist untuk mengetahui karakteristik ibu. Sedang alat yang dibutuhkan adalah lembar bantu, checklist, stopwatch, metronome, timbangan berat badan, pengukur tinggi badan. Dalam mpenelitian analisa yang digunakan adalah analisa univariat.

\section{Hasil Dan Pembahasan}

\section{Analisis Univariat}

\section{Usia}

Tabel 1 Distribusi Frekuensi Usia Ibu Hamil Trimester III Di Wilayah Kerja Puskesmas Gambirsari

\begin{tabular}{|l|c|c|}
\hline Usia & Jumlah & Prosentase \\
\hline beresiko & 12 & 12,2 \\
\hline $\begin{array}{l}\text { tidak } \\
\text { beresiko }\end{array}$ & 86 & 87,8 \\
\hline Total & 98 & 100,0 \\
\hline
\end{tabular}

Sumber : Data Primer Mei 2018

Berdasarkan tabel 1 menunjukkan bahwa mayoritas ibu hamil tri mester 3 tergolong pada tidak beresiko yaitu sebanyak 86 responden (87,8\%). Umur adalah umur individu terhitung mulai saat dilahirkan sampai saat berulang tahun. Semakin cukup umur, tingkat kematangan dan kekuatan seseorang akan lebih matang dalam berpikir dan bekerja. Bertambahnya umur seseorang maka kematangan dalam berpikir semakin baik, sehingga akan termotivasi dalam memeriksakan kehamilan dan mengetahui pentingnya ANC (Padila, 2014).

Umur sangat menentukan suatu kesehatan ibu, ibu dikatakan berisiko tinggi apabila ibu hamil berusia di bawah 20 tahun dan di atas 35 tahun. Umur di bawah 20 tahun dikhawatirkan mempunyai risiko komplikasi yang erat kaitannya dengan kesehatan reproduksi wanita, diatas 35 tahun mempunyai risiko tinggi karena adanya kemunduran fungsi alat reproduksi. Gangguan ini bukan hanya bersifat fisik karena belum optimalnya perkembangan fungsi organorgan reproduksi, namun secara psikologis belum siap menanggung beban moral, mental, dan gejolak emosional yang timbul serta kurang pengalaman dalam melakukan 
pemeriksaan ANC (Padila, 2014).

Usia aman untuk kehamilan dan persalinan adalah 20-30 tahun. Kematian maternal pada wanita hamil dan melahirkan pada usia di bawah 20 tahun ternyata 2-5 kali lebih tinggi, dari pada kematian maternal yang terjadi pada usia 2029 tahun. Kematian maternal meningkat kembali sesudah usia 30-35 tahun (Padila, 2014). Hal ini didukung oleh penelitian yang dilakukan oleh Septiani dan Zulmi (2017) tentang hubungan umur paritas dan pekerjaan ibu Dengan kejadian abortus. Berdasarkan hasil penelitian menunjukan bahwa ibu yang mengalami abortus terjadi padausia ibu hamil $<20 />35$ tahun yaitu sebesar $(65,0 \%)$ dibandingkan dengan ibu hamil yang berusia $(37,4 \%)$. Hasil uji statistik dengan kaikuadrat menghasilkan $\mathrm{p}$ value $0,000(\mathrm{P}<0,05) \quad$ berarti secara statistic adahubungan yang bermakna antara umur dengan kejadian abortus. Semakin lanjut umur wanita, semakin tipis cadangan telur yang ada, indung telur juga semakin kurang peka terhadap rangsangan gonadotropin. Makin lanjut usia wanita, maka resiko terjadi abortus, makin meningkat karena menurunnya kualitas sel telur atau ovum dan meningkatnya resiko kejadian kelainan kromosom. Selain itu, Semakin bertambahnya usia cenderung akan kehilangan massa otot dan memudahkan terjadinya akumulasi lemak tubuh (Galletta, G. 2005)

Penelitian ini didukung Wakyani (2015) cakupan yang memiliki umur 20-35 tahun (tidak resiko tinggi) sebagian besar melakukan pemeriksaan kehamilan sesuai dengan standar ( $\geq 4$ kali), dibandingkan dengan yang berumur $<20$ atau $>30$ tahun (beresiko tinggi).

\section{Parietas}

Tabel 2 Distribusi Frekuensi Parietas Ibu Hamil Trimester III Di Wilayah Kerja Puskesmas Gambirsari

\begin{tabular}{|l|c|c|}
\hline Paritas & Jumlah & Prosentase \\
\hline Primigravida & 17 & 17,3 \\
\hline Multigravida & 81 & 82,7 \\
\hline Total & 98 & 100,0 \\
\hline
\end{tabular} Sumber : Data Primer, Mei 2018
Berdasarkan tabel 2
menunjukkan bahwa dari


menunjukkan sebagian besar memilikiparietas multigravida sebanyak 81 responden(82,7\%) Paritas adalah keadaan seorang ibu yang melahirkan janin lebih dari satu orang.Ibu yang pertama kali hamil merupakan hal yang sangat baru sehingga termotivasi dalam memeriksakan kehamilannya ketenaga kesehatan. Sebaliknya ibu yang sudah pernah melahirkan lebih dari satu orang, mempunyai anggapan bahwa ia sudah berpengalaman sehingga tidak termotivasi untuk memeriksakan kehamilannya (Padila, 2014)

Parietas yang tinggi pada ibu hamil berhubungan erat dengan kesehatan kehamilan.Semakin tingginya parietas maka berdampak pada kurangnya istirahat dengan kelahiran yang dekat (Handayani, 2018).Seorang Ibu yang sering melahirkan mempunyai resiko kesehatan pada dirinya dan juga bagi kesehatan anaknya.Bayi yang dilahirkan oleh Ibu dengan paritas tinggi mempunyai risiko tinggi terhadap terjadinya abortus sebab kehamilan yang berulang-ulang dan wanita yang mempunyai paritas lebih dari 3 menyebabkan rahim tidak sehat. Dalam hal ini kehamilan yang berulang menimbulkan kerusakan pada pembuluh darah dinding uterus yang mempengaruhi sirkulasi nutrisi ke janin akan berkurang dibanding pada kehamilan sebelumnya. Keadaan ini dapat menyebabkan kematian pada bayi dan lebih besar akan mengakibatkan terjadinya abortus (Wiknjosastro, 2005).

Kejadian abortus diduga mempunyai efek terhadap kehamilan berikutnya baik pada timbulnya penyulit kehamilan maupun pada hasil kehamilan itu sendiri.Wanita dengan riwayat abrotus mempunyai resiko yang lebih tinggi untuk terjadinya persalinan premature, abortus berulang, dan berat badan lahir rendah (BBLR). (Septiani dan Zulmi, 2017)

Menurut Wiknjosastro (2005), Terjadinya abortus 
karena umur salah satu faktor yang menyebabkan terjadinya abortus. Lebih sering diatas umur 35 tahun. Reproduksi sehat dikenal bahwa usia aman untuk kehamilan dan persalinan adalah 20-35 tahun.Umur $<20 />35$ tahun lebih beresiko akan mengalami Abortus. Wanita hamil pada umur muda $(<20$ tahun) dari segi biologis perkembangan alat- alat reproduksinya belum sepenuhnya optimal.Dari segi pisikis belum matang dalam mengahadapi tuntutan beban moral, dan emosional, dan dari segi medis sering mendapat gangguan.Sedangkan pada usia lebih dari 35 tahun, elastisitas dari otot-otot panggul dan sekitarnya serta alat - alat reproduksi pada umumnya mengalami kemunduran, wanita pada usia ini mudah mengalami komplikasi antenatal diantaranya abortus". "Semakin lanjut umur wanita, semakin tipis cadangan telur yang ada, indung telur juga semakin kurang peka terhadap rangsangan gonadotropin. Makin lanjut usia wanita, maka resiko terjadi abortus, makin meningkat karena menurunnya kualitas sel telur atau ovum dan meningkatnya resiko kejadian kelainan kromosom" (Herliicha, 2011).

Selain itu, parietas juga mempengaruhi robekan perineum.Pada ibu dengan parietas satu (primipara) memiliki resiko lebih tinggi untuk mengalami robekan perineum dari pada ibu dengan parietas lebih dari satu. Hal ini dikarenakan jalan lahir yang belum pernah dilalui oleh kepala bayi sehingga otot-otot perineum belum merenggang (Prawirohardjo, 2013)

\section{Tingkat Aktivitas}

Tabel 3 Distribusi Frekuensi Tingkat Aktivitas Ibu Hamil Trimester III Di Wilayah Kerja Puskesmas Gambirsari

\begin{tabular}{|l|r|r|}
\hline $\begin{array}{l}\text { Tingkat } \\
\text { aktivitas }\end{array}$ & Jumlah & Prosentase \\
\hline Tidak aktif & 18 & 18,4 \\
\hline Aktif & 80 & 81,6 \\
\hline Total & 98 & 100,0 \\
\hline
\end{tabular}

Sumber : Data Primer, Mei 2018

Berdasarkan tabel 4.5

menunjukkan bahwa tingkat 
aktifitas aktif pada ibu hamil tri mester 3 aktif sebesar 80 responden $(81,6 \%)$.

Saat masuk ke trimester pertama maka ibu hamil akan merasakan berbagai gejala gangguan kehamilan yang kurang nyaman seperti mual dan muntah. Selain itu, beberapa gangguan yang berhubungan dengan fisik juga sangat sering muncul.Untuk melindungi kondisi ibu dan janin sebaiknya menghindari beberapa aktivitas berbahaya untuk ibu hamil yaitu terkena kontaminasi udara beracun, merokok, konsumsi alkohol, larangan diet untuk ibu hamil, sauna atau berendam dalam air panas, mendapatkan tekanan pikiran / pemicu stres (Septiana, 2016).

Menurut Almatsier dalam Sutri 2014), pengertian aktifitas fisik ialah gerakan fisik yang dilakukan oleh otot tubuh dan sistem penunjangnya. Menurut WHO (2010), aktifitas fisik adalah setiap gerakan tubuh yang dihasilkan oleh otot rangka yang memerlukan pengeluaran energi. Aktifitas fisik yang tidak ada (kurangnya aktivitas fisik), merupakan faktor risiko independen untuk penyakit kronis, dan secara keseluruhan diperkirakan menyebabkan kematian secara global.

Menurut Kristanti dalam sutri 2014, aktifitas fisik adalah setiap pergerakan tubuh akibat aktifitas otot-otot skeletal yang mengakibatkan pengeluaran energi.Aktivitas fisik terdiri dari aktifitas selama bekerja, tidur, dan pada waktu senggang. Setiap orang melakukan aktifitas fisik, atau bervariasi antara individu satu dengan yang lain bergantung gaya hidup perorangan dan faktor lainnya seperti jenis kelamin, umur, pekerjaan, dan lain-lain. Aktifitas fisik sangat disarankan kepada semua individu untuk menjaga kesehatan terutama pada ibu hamil.Saat hamil, wanita tentunya harus lebih berhati-hati dalam melakukan kegiatan dan aktivitasnya seharihari. Tak sedikit wanita yang berhenti berolahraga karena 
khawatir hal tersebut dapat membahayakan kehamilannya.

Aktivitas fisik sangat berpengaruh terhadap tingkat kebugaran jasmani seseorang.Salah satu aktivitas fisik yang baik untuk meningkatkan kebugaran jasmani adalah olahraga.Olahrga yang ideal yaitu olahraga yang meningkatkan ketahanan jantung dan paru-paru, disamping juga melatih ketahanan dan kekuatan otot.Ukuran olahraga dapat dinilai berdasarkan jenis olahraga yang dilakukan, frekuensi, intensitas, dan lamanya berolahraga.Status gizi merupakan salah satu faktor yang harus diperhatikan mengingat kurangnya status gizi dapat mengakibatkan kualitas fisik yang rendah yang dapat berdampak pada penurunan tingkat kebugaran jasmani (Suroto, 2015).

Sementara itu, di sisi lain, terkadang ibu hamil semakin sering tidur dan makan lebih banyak.Kebiasaan semacam itu justru memicu datangnya beberapa penyakit seperti diabetes atau gestational.Karena itu, ibu hamil juga diwajibkan menyisihkan waktu untuk berolahraga ringan agar tubuh dan janinnya tetap bugar. Aktivitas yang membuat badan ibu hamil tetap bugar selama kehamilan muda akan memberikan energi dan membuat ibu hamil semakin kuat ketika melahirkan. Berikut adalah beberapa jenis olah raga dan aktivitas yang aman untuk ibu yang sedang hamil yaitu jalan santai, berenang, yoga, olahraga statis, relaksasi menggunakan aroma-terapi, berbelanja, melakukan pekerjaan rumah, membaca dan senam hamil (Handayani, 2015)

Aktivitas fisik diketahui berperan penting untuk mencegah obesitas dan memegang peranan terhadap distribusi lemak tubuh.Aktivitas fisik yang memadai dapat menurunkan persentasi lemak tubuh yang selanjutnya dapat mengurangi risiko menderita 
obesitas dan penyakit kardiovaskuler (Anam, 2010).

\section{Indeks Massa Tubuh (IMT)}

Tabel 4.4 Distribusi Frekuensi Indeks Massa Tubuh (IMT) Ibu Hamil Trimester III Di Wilayah Kerja Puskesmas Gambirsari

\begin{tabular}{|c|c|c|}
\hline \multicolumn{1}{|l|}{ IMT } & Jumlah & Prosentase \\
\hline Rendah & 3 & 3,1 \\
\hline Normal & 74 & 75,5 \\
\hline Tinggi & 12 & 12,2 \\
\hline Obesitas & 9 & 9,2 \\
\hline Total & 98 & 100,0 \\
\hline
\end{tabular}

Sumber : Data Primer, Mei 2018

Berdasarkan tabel 4.3

menunjukkan bahwa ibu hamil trimester 3 mayoritas memiliki IMT normal sebanyak 74 responden (75,5\%). Menurut buku asuhan kebidanan kehamilan (Saryono, 2010) yaitu mengatakan kenaikan berat badan selama hamil 9-13,5 kg yaitu pada trimester 1 kenaikan berat badan minimal $0,7-1,4$ $\mathrm{kg}$, pada trimester 2 kenaikan berat badan $4,1 \mathrm{~kg}$ dan pada trimester 3 kenaikan berat badan 9,5 kg.

IMT merupakan cara termudah memperkirakan obesitas yang berhubungan tinggi dengan massa lemak tubuh serta penting untuk mengidentifikasi pasien obesitas yang mempunyai risiko komplikasi medis (Pudjiadji, 2010). Rendahnya aktivitas fisik menjadi faktor risiko berbagai penyakit kronis dan diperkirakan menyebabkan kematian secara global.

Aktivitas fisik adalah setiap gerakan tubuh yang dihasilkan oleh otot rangka dan memerlukan pengeluaran energi.Aktivitas fisik yang teratur dan benar sangat penting bagi pemeliharaan kesehatan fisik, mental dan mempertahankan kualitas hidup agar tetap sehat dan bugar.Rendahnya aktivitas fisik menyebabkan penumpukan energi oleh tubuh dalam bentuk lemak. Jika hal ini terjadi secara terus-menerus akan menyebabkan peningkatan IMT. Peningkatan IMT menjadi faktor risiko utama terjadinya penyakit kronis seperti penyakit kardiovaskular (jantung dan stroke), diabetes, gangguan tulang dan otot serta penyakit keganasan. 
Menurut Saryono (2010) berat badan dilihat dari Quetet atau Body massa index (Indeks Massa Tubuh $=$ IMT). Ibu hamil dengan berat badan dibawah normal sering dihubungkan dengan abnormalitas kehamilan, berat badan lahir rendah.Sedangkan berat badan overweight meningkatkan resiko atau komplikasi dalam kehamilan seperti hipertensi, janin besar sehingga terjadi kesulitan dalam persalinan.

\section{Riwayat}

Persalinan

\section{Sebelumnya}

Tabel 4.5 Distribusi Frekuensi Riwayat Persalinan Sebelumnya Ibu Hamil Trimester III Di Wilayah Kerja Puskesmas Gambirsari

\begin{tabular}{|l|r|r|}
\hline $\begin{array}{l}\text { Riwayat } \\
\text { persalinan }\end{array}$ & Jumlah & Prosentase \\
\hline $\begin{array}{l}\text { Belum } \\
\text { pernah } \\
\text { melahirkan }\end{array}$ & 15 & 15,3 \\
\hline Spontan & 79 & 80,6 \\
\hline $\begin{array}{l}\text { Secsio } \\
\text { cesaria }\end{array}$ & 4 & 4,1 \\
\hline Total & 98 & 100 \\
\hline
\end{tabular}

Sumber : Data Primer, Mei 2018

$$
\text { Berdasarkan tabel } 4.5
$$
menunjukkan bahwa ibu hamil trimester 3 sebagian besar mempunyai riwayat persalinan spontan yaitu 79 responden $(80,6 \%)$

Proses persalinan yang normal akan dimulai dari adanya kontraksi yang ditandai dengan terjadi pembukaan servik secara bertahap dan akan diakhiri dengan pengeluaran atau kelahiran plasenta dengan lengkap sedangkan persalinan yang tidak normal yaitu persalinan yang menggunakan bantuan atau alat bantu dan tidak dengan kekuatan sendiri (Sulistyawati, 2010)

\section{Tingkat kebugaran}

Tabel 4.6 Distribusi Frekuensi Riwayat Persalinan Sebelumnya Ibu Hamil Trimester III Di Wilayah Kerja Puskesmas Gambirsari

\begin{tabular}{|c|c|c|}
\hline $\begin{array}{l}\text { Tingkat } \\
\text { kebugaran }\end{array}$ & Jumlah & Prosentase \\
\hline Rendah & 88 & 89,9 \\
\hline Kurang & 10 & 10,2 \\
\hline Total & 98 & 100 \\
\hline
\end{tabular}

Berdasarkan tabel 4.6 menunjukkan bahwa ibu hamil trimester 3 sebagian besar mempunyai tingkat kebugaran rendah yaitu 88 responden $(89,9$ $\%)$ 
Berbagai unsur kebugaran yang saling berhubungan ialah daya tahan cardiovaskuler, daya tahan otot, serta kelenturan dan komposisi tubuh. Ha ini didukung oleh penelitian yang dilakukan Carnethon (2005), diperoleh hasil bahwa salah satu komponen kebugaran ialah ketahanan cardiovaskular yang rendah berhubungan dengan tingginya tingkat mortalitas dan morbiditas populasi pada kelompok usia 19-49 tahun. Penelitian ini juga menunjukkan bahwa orang yang memiliki tingkat kebugaran rendah cenderung memiliki kadar lipoprotein dan tekanan darah lebih tinggi dibandingkan dengan responden yang memiliki tingkat kebugaran lebih tinggi. Hal ini berkaitan dengan kebugaran yang merupakan komponen kesehatan esensial dan sebagai prasyarat untuk organisme berinteraksi secara optimal dalam berbagai stimulasi di lingkungan sekitar (Camethon, dkk, 2005).

Simpulan dan saran. Gambaran karakteristik ibu hamil di Wilayah Puskesmas Gambirsari Surakarta mayoritas ibu hamil tri mester 3tergolong tidak beresiko,sebagian besar memiliki parietas multigravida, tingkat aktifitas pada aktifitas tergolong aktif, mayoritas memiliki IMT normal, sebagian besar mempunyai riwayat persalinan spontan.Tingkat kebugaran jasmani ibu hamil di Wilayah Puskesmas Gambirsari Surakarta sebagian besar mempunyai tingkat kebugaran rendah. Untuk itu perlu dilakukan upaya untuk meningkatkan kebugaran seperti senam hamil yang dipantau oleh tenaga kesehatan .

\section{Daftar Pustaka}

Anam. 2010. Pengaruh Intervensi Diet Dan Olahraga Terhadap Indeks Massa Tubuh, Kesegaran Jasmani, Hscrp Dan Profil Lipid Pada Anak Obesitas Thesis. Program Pasca Sarjana Magister Ilmu Biomedik Dan Program Pendidikan Dokter Spesialis1 Ilmu Kesehatan Anak. Universitas Diponegoro. Semarang.
Dinas Kesehatan Kota Surakarta.2014. Profil Kesehatan Kota Surakarta Tahun 2014.Surakarta.

Departemen Kesehatan RI. 2015. Profil Kesehatan 
IndonesiaTahun 2015. Jakarta.

Dinas Kesehatan Provinsi Jawa Tengah. 2015. Profil Kesehatan Provinsi Jawa Tengah Tahun 2015. Semarang.Oktober 2010.Diakses pada tanggal 30 Juli 2016.

Galletta, G. 2005. Emedicine Health. Available at: http://www.emedicinehealth.co m. Diakses tanggal 18 Juni 2018.

Handayani, I Dan Suryani, P. 2018. Senam Hamil Dan Ketidaknyamanan Ibu Hamil Trimester Ketiga.Midwife Journal. Vol 5 No 1.

Padila,2014.Buku Ajar Keperawatan Maternitas, Yogyakarta

Pudjiadi, A.H, B.Handryastuti, S. 2010. Pedoman pelayanan Medis Ikatan Dokter Anak Indonesia.Jakarta: IDAI

Prawirohardjo, S. 2013. Pelayanan Kesehatan Maternal Dan Neonatal.Jakarta : PT. Bina Pustaka Sarwono Prawirohardjo

Saryono. 2010. Asuhan Kebidanan I: Kehamilan. Nuha Medika. Yogyakarta

Septiani, Z. 2017. Hubungan Umur Paritas Dan Pekerjaan Ibu Dengan Kejadian Abortus
Sutri. 2014. Hubungan Aktivitas Fisik Dengan Kesegaran Jasmani Pada Remaja Puasa

Suroto, S J. 2015. Hubungan Indeks Massa Tubuh Dan Frekuensi Olahraga Terhadap Kebugaran Jasmani Pekerja Konstruksi Di PT. PP (Persero) Tbk Proyek Apartemen Pinnacle Semarang.Jurnal Kesehatan Masyarakat. Vol 3. No 1..

Sulistyawati, A. 2012.Asuhan Kebidanan Kehamilan. Jakarta: Salemba Medika

Walyani, Elizabeth Siwi. 2015. Asuhan Kebidanan pada Kehamilan. Cetakan Pertama.Pustakabarupress. Yogyakarta

Wiknjosastro, H. 2005. Ilmu Kebidanan.Jakarta : Yayasan Bina Pustaka

WHO. 2010. Physical Activity. Available

at :http://www.who.int/topics/ physical activity/en/ diakses tanggal 12 juni 2018. 